\title{
STUDY ON MECHANICAL PROPERTIES OF A356 ALLOYS ENHANCED WITH PREFORMED THIXOTROPIC STRUCTURE
}

Shueiwan H. Juang

Department of Mechanical and Mechatronic Engineering, National Taiwan Ocean University, Keelung, Taiwan, R.O.C., shjuang@mail.ntou.edu.tw

Shyh-Ming Wu

Costco \#690, U.S.A.

Follow this and additional works at: https://jmstt.ntou.edu.tw/journal

Part of the Mechanical Engineering Commons

\section{Recommended Citation}

Juang, Shueiwan H. and Wu, Shyh-Ming (2008) "STUDY ON MECHANICAL PROPERTIES OF A356 ALLOYS ENHANCED WITH PREFORMED THIXOTROPIC STRUCTURE," Journal of Marine Science and Technology. Vol. 16: Iss. 4, Article 5. DOI: $10.51400 / 2709-6998.2011$

Available at: https://jmstt.ntou.edu.tw/journal/vol16/iss4/5

This Research Article is brought to you for free and open access by Journal of Marine Science and Technology. It has been accepted for inclusion in Journal of Marine Science and Technology by an authorized editor of Journal of Marine Science and Technology. 


\section{STUDY ON MECHANICAL PROPERTIES OF A356 ALLOYS ENHANCED WITH PREFORMED THIXOTROPIC STRUCTURE}

\section{Acknowledgements}

This research was sponsored by Mechanical Industry Research Laboratories of Industrial Technology Research Institute in Taiwan. All tests were run using the equipment at Materials and Electro-optical Division of Chung-Shan Institute of Science \& Technology in Taiwan. 


\title{
STUDY ON MECHANICAL PROPERTIES OF A356 ALLOYS ENHANCED WITH PREFORMED THIXOTROPIC STRUCTURE
}

\author{
Shueiwan H. Juang* and Shyh-Ming Wu**
}

Key words: A356 alloy, thixotropic structure, mechanical properties.

\begin{abstract}
A preformed A356 alloys with thixotropic structure (designated SSM-A356) was systematically studied on mechanical properties in order to establish the database for further investigations in forming and heat treatment. Because of the specific microstructure and characteristics, the heat treatment conditions of SSM-A356 were explored through the observations of microstructure and the measurement of micro-hardness. In the investigation of heat treatment, it was observed that the eutectic silicon was refined and spheroidized which is unlikely for conventional processing. The mechanical testing results showed that the yield and ultimate tensile strength of SSM-A356 were respectively around $115 \%$ and $34 \%$ greater than those of conventional A356, and the elongation was also 2-3 times larger. According to the analysis of fracture mode via fatigue test, the crack propagation was in the way of trans-granular which is a typical type of ductile fracture. Thus, an excellent ductility for SSM-A356 was expected. From the experimental analysis results, it could be concluded that the superior mechanical behaviors of SSM-A356 are basically attributed to the refinement of microstructure and the spheroidization of eutectic silicon. This structure can be maintained during forming by further processing of die or squeeze casting.
\end{abstract}

\section{INTRODUCTION}

Metals were processed at either solid or molten state in traditional metal forming processes. The major near-net-shape forming process at molten state is die casting, which has the advantages of high productivity and dimensional accuracy. However, porosity is commonly found in die cast parts, thus applications are limited. Semi-solid forming processes provide a practical way to overcome the problems of porosity.

In a hot-tearing experiment, Flemings et al. found out that a

Paper submitted 04/24/07; accepted 11/30/07. Author for correspondence: Shueiwan H. Juang (e-mail: shjuang@mail.ntou.edu.tw).

*Department of Mechanical and Mechatronic Engineering, National Taiwan Ocean University, Keelung, Taiwan, R.O.C.

** Costco \#690, U.S.A. slurry with near spherical primary crystals suspending in the liquid metal matrix would form in a partially-solidified metallic alloy if continuous shearing was applied [5]. The material can have a good fluidity when the solid fraction is as high as $60 \%$. Thus the metallic alloy can be formed into a shape at partially-solidified state.

When a heat-treatable A356 aluminum alloy undergoes precipitation hardening (age-hardening), fine precipitants will dissolve completely in saturated matrix to achieve high strength in material [2]. The processing temperature should be kept close to the eutectic temperature of the alloy in order to obtain maximum amount of solid solution [4], while the processing time should be long enough to allow all solute atoms to dissolve into the matrix. The solid solution should then be quenched at a high cooling rate to reach a low temperature and obtain a super-saturated solid solution. The quench interval should be short in order to prevent deterioration in material mechanical properties such as tensile strength, yield strength and elongation [2, 3]. It is suggested in the ASTM standard that the water quench has to be finished in 10 seconds to obtain uniform $\mathrm{Mg}_{2} \mathrm{Si}$ precipitation and better mechanical characteristics. When the super-saturated solid solution undergoes aging treatment, a large amount of small and uniformly-distributed precipitants will appear thus the mechanical properties of the material can be improved. Uniform and delicate $\mathrm{Mg}_{2} \mathrm{Si}$ precipitants can be obtained in the matrix of a heat-treatable $\mathrm{Al}-\mathrm{Si}-\mathrm{Mg}$ casting part with T6 treatment, leading to improvements in its tensile strength, elongation and toughness [7, 8].

A preformed A356 aluminum alloy with thixotropic structure (designated SSM-A356) was used in this study. Two sets of ASTM standard specimens were first prepared, of which one set was T6 treated with processing conditions proposed by $\mathrm{Wu}$ [9]. Tensile, impact and fatigue tests were performed on the T6-treated and non-treated specimens and the results were compared.

\section{TEST EQUIPMENT AND METHODS}

Raw materials used in this study were obtained from an SSM-MHD caster in Europe. Two sets of ASTM specimens were prepared. One set underwent a solid solution treatment at $540{ }^{\circ} \mathrm{C}$ for 12 hours, water quench, and then an aging treatment at $155^{\circ} \mathrm{C}$ in air for $12 \sim 19$ hours. Another set was as-cast without 


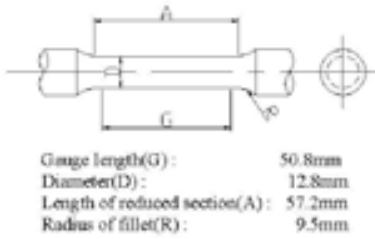

(a)

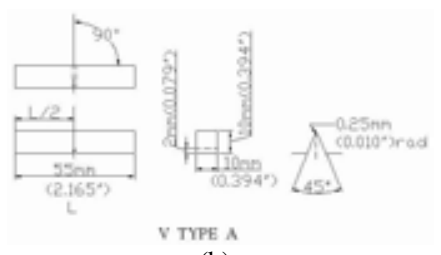

(b)
Fig. 1. Test specimens of SSM-A356: (a) tensile test, (b) impact and fatigue tests.

any treatment. The two sets of specimens were used for tensile, impact and fatigue testing as follows:

\section{Tensile Test}

Standard test bars shown in Fig. 1(a) were machined following ASTM B557-94 standard [1], with a length of 155 160 $\mathrm{mm}$. Diameters at two ends and center portion are $18 \mathrm{~mm}$ and $12.8 \mathrm{~mm}$, respectively. Experiments were done using a Zwick-1475 material testing machine. Specimens were held at two ends by automatic hydraulic clamps, and the test conditions were input from a computer. Cross-head speed was $1 \mathrm{~mm} / \mathrm{min}$, and the gage length was set to $50.8 \mathrm{~mm}$.

\section{Impact Test}

Specimen dimensions were $10 \times 10 \times 55 \mathrm{~mm}$ with a V-shape notch, shown in Fig. 1(b), based upon ASTM E8-96 standard [1]. Tests were performed using a CHARPY-TINIUS OLSEN 64 impact testing machine with impact energy of swinging pendulum 358 Joule, impact speed $5.12 \mathrm{~m} / \mathrm{s}$ and testing temperature $20{ }^{\circ} \mathrm{C}$.

\section{Fatigue Test}

Dimensions of specimens prepared according to ASTM E812-91 standard [1] were the same as in impact tests. An MTS-810.15 fatigue testing machine was used to perform the 3-point bending tests with a 40- $\mathrm{mm}$ span at the bottom. The maximum loading $F_{\max }$ was $1.2 \sim 2.5 \mathrm{kN}$, radius $0.1 R$, frequency $3 \mathrm{~Hz}$, and loading frequency 7000 25000 cycles.

\section{RESULTS AND DISCUSSIONS}

The results obtained from the two sets of SSM-A356 specimens conducting on the tensile, impact and fatigue tests under the same conditions were discussed as follows.

\section{Tensile Test}

The tensile properties of SSM-A356 under different states are given in Table 1. The yield strength of as-cast SSM-A356 was only $128 \mathrm{MPa}$, which is a little lower than that of conventional alloys, but the tensile strength $254 \mathrm{MPa}$ was close to that of conventional one. It was noted that the elongation of as-cast SSM-A356 was $13.3 \%$, which is about 2 3 times of the conventional alloys. After applying the T6 treatment, solid solution treatment at $540{ }^{\circ} \mathrm{C}$ for 12 hours and aging treatment at $155{ }^{\circ} \mathrm{C}$ for 12 hours, the elongation of SSM-A356 was reduced to $11.5 \%$, however, the yield and tensile strength were dramati-
Table 1. Comparison of strength and elongation under different states for SSM-A356 (T6 treatment: solution treatment $540{ }^{\circ} \mathrm{C} / 12$ hrs and aging temperature $155^{\circ} \mathrm{C}$ ).

\begin{tabular}{|c|c|c|c|}
\hline $\begin{array}{c}\text { State of } \\
\text { specimen }\end{array}$ & $\begin{array}{c}\text { Yield } \\
\text { strength } \\
(\mathrm{MPa})\end{array}$ & $\begin{array}{c}\text { Ultimate } \\
\text { strength } \\
(\mathrm{MPa})\end{array}$ & $\begin{array}{c}\text { Elongation } \\
(\%)\end{array}$ \\
\hline $\begin{array}{c}\text { ASTM specs } \\
\text { value* }\end{array}$ & $165 \sim 185$ & $228 \sim 262$ & $3.5 \sim 5.0$ \\
\hline As-cast & 128 & 254 & 13.3 \\
\hline $\begin{array}{c}\text { T6 treatment } \\
\text { (aging 12 hr) }\end{array}$ & 276 & 341 & 11.5 \\
\hline $\begin{array}{c}\text { T6 treatment } \\
\text { (aging 19 hr) }\end{array}$ & 280 & 343 & 10.8 \\
\hline
\end{tabular}

Note: *A356 without thixotropic structure after T6 treatment.

cally increased to $276 \mathrm{MPa}$ and $341 \mathrm{MPa}$, respectively. That is, there is an improvement about $115 \%$ and $34 \%$ on yield and tensile strength, respectively, although having a $14 \%$ reduction on elongation. It also indicated that the changes in mechanical properties were limited as the aging duration was changed from 12 hours to 19 hours.

The improvement on mechanical behaviors of SSM-A356 was basically attributed to the factors such as:

A. Reduction of macro-defects. The hydrogen dissolution into aluminum alloys is increased significantly in a liquid state, and leads to a large amount of gas porosity during solidification stage. However, SSM-A356 is formed and solidified in a semi-solid state. The hydrogen dissolution is relatively decreased, leading to less gas porosity. Moreover, the shrinkage porosity is also reduced due to lower forming temperatures.

B. Spheroidization of eutectic silicon. The spherodization of eutectic silicon in SSM-A356 is via solid diffusion, which is driving in virtue of the difference of silicon composition in the liquid state and in the solid solution. During the phase transformation, eutectic silicon is refined and almost completely spheorodized. This causes that the crack was not propagating along the sharp interface of eutectic silicon and matrix. Therefore, SSM-A356 revealed better strength and elongation.

C. Refinement of microstructure. The microstructure of SSM-A356 was refined via a specific process, either mechanical stirring or MHD. The lattice space was about 10 $\mu m$, which is much smaller than that of material without thixotropic structure. In addition, the distribution of eutectic silicon was uniform with a particle size around 3 5 $\mu \mathrm{m}$. Material with particle dispersion strengthening effect would be improved on strength significantly.

\section{Impact Test}

The toughness of SSM-A356 is listed in Table 2. The impact value of as-cast SSM-A356 was 11.5 Joule, which is much higher than that of conventional A356 with T6 treatment, having 3.8 Joule only. After applying T6 treatment to as-cast SSM-A356, the impact value was dropped to 4 Joule, which is close to that of conventional alloys. As compared to the elongation with a slight reduction before and after T6 treatment, this 
Table 2. Comparison of impact value under different states for SSM-A356 (T6 treatment: solution treatment $540{ }^{\circ} \mathrm{C} / 12 \mathrm{hr}$ and aging temperature $155^{\circ} \mathrm{C}$ ).

\begin{tabular}{|l|c|}
\hline State of specimen & Impact value (Joule) \\
\hline ASTM spec value* & 3.8 \\
\hline As-cast & 11.5 \\
\hline T6 treatment (aging 19 hr) & 4.0 \\
\hline
\end{tabular}

Note: *A356 without thixotropic structure after $\mathrm{T} 6$ treatment.

Table 3. Comparison of crack propagation under different states for SSM-A356 (Radius: 0.1R, frequency: 3Hz).

\begin{tabular}{|c|c|c|c|c|}
\hline $\begin{array}{c}\text { Specimen } \\
\text { No. }\end{array}$ & $\begin{array}{c}\text { State of } \\
\text { specimen }\end{array}$ & $\begin{array}{c}\text { Maximum } \\
\text { load }(\mathrm{kN})\end{array}$ & $\begin{array}{c}\text { Load } \\
\text { cycles }\end{array}$ & $\begin{array}{c}\text { Crack length } \\
(\mathrm{mm})\end{array}$ \\
\hline \multirow{2}{*}{1} & \multirow{2}{*}{ As-cast } & 2.5 & 7,000 & 2.0 \\
\cline { 3 - 5 } & & 2.5 & 300 & - \\
\hline \multirow{2}{*}{2} & \multirow{3}{*}{ As-cast } & 1.5 & 7,000 & 1.5 \\
\cline { 3 - 5 } & & 1.5 & 1,300 & 2.0 \\
\cline { 3 - 5 } & \multirow{2}{*}{3} & 1.2 & 5,300 & 2.5 \\
\hline \multirow{2}{*}{3} & T6 treat- & 2.5 & 22,500 & 1.0 \\
\cline { 3 - 5 } & ment* & 2.0 & 3,000 & 2.5 \\
\hline
\end{tabular}

Note: *Solution condition: $540{ }^{\circ} \mathrm{C} / 12 \mathrm{hr}$ and aging condition: $155^{\circ} \mathrm{C} / 19$ hr.

obvious drop on toughness of SSM-A356 after T6 treatment might be related to strain rate under the test and fracture mechanism of almost completely spheorodized eutectic silicon. Further study on improvement of toughness is required to be conducted for reaching an optimum treatment conditions upon material strength and toughness.

\section{Fatigue Test}

A series of fatigue tests, using impact test specimens, was conducted to investigate the fracture mechanism of SSM-A356 under different loads. In the test a natural crack was initialized on the specimens, then following a fatigue test. If the specimen was not broken off, an optical electron microscope (OEM) was utilized to observe and measure the crack propagation with different multiplication factors. The observed results are showed in Table 3.

Table 3 indicated that Specimen 1 was as-cast SSM-A356 under a fatigue load of $2.5 \mathrm{kN}$. A natural crack was appeared with $2.0 \mathrm{~mm}$ in length as the fatigue frequency at 7,000 cycles. If the test was continued under the same load, the test specimen was broken off at 300 cycles more. Crack propagation could not be observed from this test.

Specimen 2 in Table 3 was also as-cast SSM-A356 under an initial fatigue load $1.5 \mathrm{kN}$. A natural crack appeared with $1.5 \mathrm{~mm}$ in length as the fatigue frequency at 7,000 cycles. The crack length propagated to $2.0 \mathrm{~mm}$ as the test was continued 1,300 cycles more under the same load. Then, the test was continued 5,300 cycles added under a new load $1.2 \mathrm{kN}$, leading the crack with $2.5 \mathrm{~mm}$ in length. Fig. 2 showed the crack propagation of Specimen 2 under the combination load. It was evident that there were two segments with different width in the crack, shown in Fig. 2(a). The wide one was formed via the load $1.5 \mathrm{kN}$ and the narrow one via $1.2 \mathrm{kN}$. Fig. 2(b) showed that the crack propagation was in the way of trans-granular, rather than along

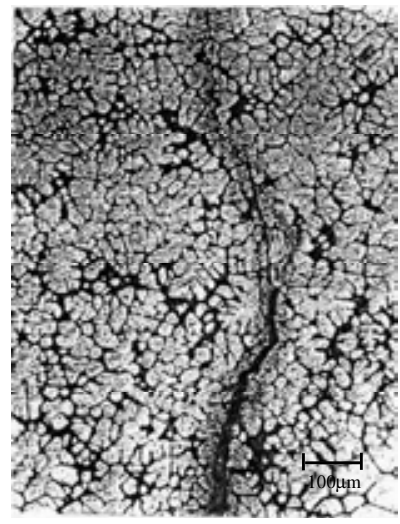

(a)

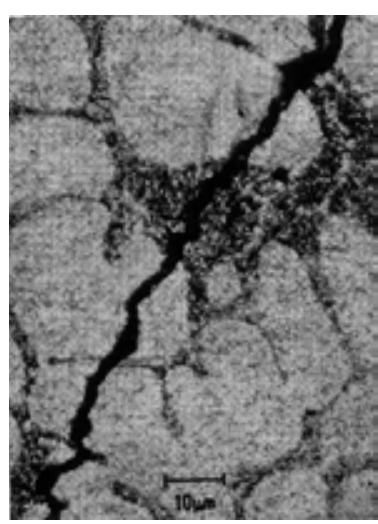

(b)
Fig. 2. Crack propagation of as-cast SSM-A356 under initial load $1.5 k N$ and $1.2 k N$ followed, (a) x100 and (b) $\mathrm{x} 1000$.

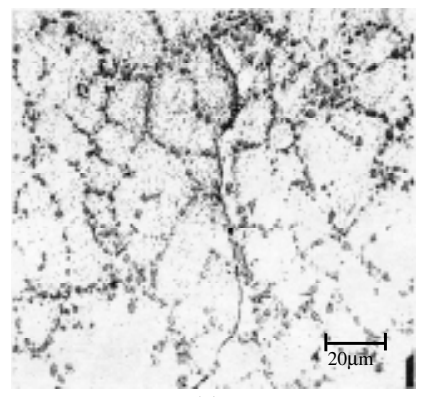

(a)

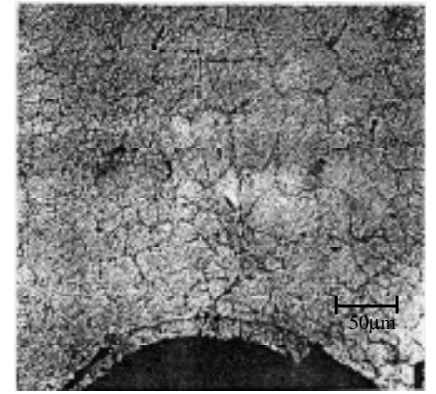

(b)
Fig. 3. Crack propagation of SSM-A356 with T6 treatment, (a) fatigue load $2.5 k N(x 500)$ and (b) fatigue loads $2.5 k N$ and then $2.0 k N$ (x200).

the grain boundary. This type of fracture mode led SSM-A356 with superior elongation and strength.

Specimen 3 in Table 3 was T6 treated SSM-A356, solid solution treatment at $540{ }^{\circ} \mathrm{C}$ for 12 hours and aging treatment at $155{ }^{\circ} \mathrm{C}$ for 12 hours, which showed a significant raise on the fatigue property. A natural crack with $1.0 \mathrm{~mm}$ in length only appeared as the fatigue frequency at 22,500 cycles under a fatigue load $2.5 \mathrm{kN}$. The crack propagation also revealed the typical type of trans-granular fracture, shown in Fig. 3(a). Following the test with a fatigue load $2.0 \mathrm{kN}$, Fig. 3(b) showed that the crack propagation in accordance with the trans-granular fracture mode was more evident as 30,000 cycles more applied.

\section{CONCLUSIONS}

Raw materials used in this study were SSM-A356, which were categorized into two sets of ASTM specimens. One set underwent a T6 treatment, solid solution treatment at $540{ }^{\circ} \mathrm{C}$ for 12 hours and aging treatment at $155^{\circ} \mathrm{C}$ for 12 hours, and another set was as-cast without any treatment. Two sets of specimens were investigated under the same conditions for tensile, impact and fatigue testing. The significant results were outlined as follows:

1. It explored that both yield strength and ultimate tensile strength were substantially increased for T6 treated SSM-A356. The measured yield strength and ultimate ten- 
sile strength were respectively about $115 \%$ and $34 \%$ greater than those of conventional alloys. It was also observed that the elongation was 2 3 times larger than the ASTM specified data, also leading to improvements on the relative fatigue properties.

2. It showed that the improvement on the mechanical properties of SSM-A356 was correlated to the reduction of gas and shrinkage porosity, refinement of microstructure, and spheroidization of eutectic silicon. This result was same as that addressed by Saigal [6]. That is, the mechanical properties were affected by the shape and distribution of silicon inside the aluminum matrix. In general, a uniform distribution of silicon with refinement and spheroidization would go towards to improvement on elongation, impact and fatigue due to lower interface energy. For SSM-A356, it had a fine thixotropic structure during the preparation of raw material and its following processing. The improvement on the impact and fatigue properties as compared to conventional A356 would be expected.

3. According to the analysis of fracture mode via fatigue test, it can be concluded that the crack propagation was in the way of trans-granular, which is a typical type of ductile fracture, rather than along the boundary between eutectic silicon and matrix. This phenomenon was observed for SSM-A356 with either T6 treatment or not.

\section{ACKNOWLEDGEMENT}

This research was sponsored by Mechanical Industry Research Laboratories of Industrial Technology Research Institute in Taiwan. All tests were run using the equipment at Materials and Electro-optical Division of Chung-Shan Institute of Science \& Technology in Taiwan.

\section{REFERENCES}

1. Annual Book of ASTM Standards, American Society for Testing and Materials (ASTM) (1994)

2. Apelian, D., Shivkumar, S., and Sigworth, G., "Fundamental aspects of heat treatment of cast Al-Si-Mg Alloys," American Foundry Society Transaction, Vol. 97, pp. 727-742 (1989)

3. Chamberlain, B. and Zabek, V. J., "Reappraisal of the tensile properties of Al-Si-Mg casting alloys," American Foundry Society Transaction, Vol. 81, pp. 322-327 (1973).

4. Hatch, J. E., Ed. Aluminum properties and physical metallurgy, American Society for Metals (1984).

5. Metz, S. A. and Flemings, M. C., "A fundamental study of hot tearing," American Foundry Society Transaction, Vol. 78, pp. 453-460 (1970).

6. Saigal, A., "Stress and strain distributions in two-phase Aluminum-Silicon alloys," American Foundry Society Transaction, Vol. 94, pp. 219-224 (1986).

7. Shivkumar, S., Keller, C., and Apelian, D., "Aging behavior in cas Al-Si-Mg alloy," American Foundry Society Transaction, Vol. 98, pp. 905-911 (1990).

8. Sinfield, R. and Harris, D. A., Journal of Australian Institute of Metals, Vol. 20 (1), pp. 44-47 (1975).

9. Wu, S. M., The Study on Physical and Mechanical Properties of an A356 Aluminum Alloy with Thixotropic Properties, M. S. Thesis, National Taiwan Ocean University, Taiwan (1998). 